\title{
Impact of Mobile Shopping Behaviour: Implications for Designing Mobile Marketing Strategy
}

\author{
Dr.R. Mary Metilda and Malathi
}

\begin{abstract}
Mobile commerce, by the end of 2017, will be $24.4 \%$ of overall Ecommerce revenues. Mobile app stores have emerged as vital part of Mcommerce. It is projected to grow to \$76.5 billion in 2017 according to a survey from Statistica, February, 2015. In India, as on April 2015, mcommerce accounted $72 \%$ of overall ecommerce.
\end{abstract}

This indicates that the mobile shopping channel has emerged as an influential medium for connecting customers with retailers and ultimately in generating sales. Mobile internet services can provide e-commerce activities in a different way than existing shopping services.

This study analyses the critical determinants of mobile shopping behaviour which includes the personality traits, motivation, and ease of use, perceived usefulness and attitude towards purchase using smart phones. It explains about these factors that might influence a mobile shopper's purchase intention. A conceptual model was proposed to illustrate the relationships between the factors of mobile shopping and the effect of drivers and impediments of online shopping using smart phones on these factors, such as, ease of use, perceived usefulness, and attitude towards purchase using mobile phones. The secondary data from the literature were used to explain and explore the relationship between these factors. The discussion on managerial implications suggested the retailers to predict consumers shopping behaviour for their products and to design the personalized mobile marketing strategy to gain more benefits from existing customers and to improve the motivation of the potential mobile shoppers.

\section{INTRODUCTION}

$\mathrm{T}$ HE huge development in the Internet services and the increase in their quality have immensely contributed to electronic trade, known as e-commerce. According to Statista, worldwide business-to-consumer (B2C) e-commerce sales surpassed US\$2.3 trillion in 2014. Current statistics show that 40 percent of Internet users have made at least one e-commerce transaction, a number that amounts to close to 1 billion users. The advancement in mobile phone and social commerce promise even higher penetration rates for e-commerce in the following years.

Dr.R. Mary Metilda, Professor, Department of Management Studies, Sri Ramakrishna Engineering College. E-mail:metilda@srec.ac.in

Malathi, Research Scholar, Bharathiar University, Coimbatore. E-mail:mathimba12@gmail.com

DOI: 10.9756/BIJIEMS.7466
Mobile devices enable the companies to connect to their consumers on the go and on a 24-hour basis (Emarketer, 2013). Research by Euromonitor (2013) identified that consumers who were increasingly favour seeking shopping information on their smartphones rather than consulting a salesperson or relying on advertisements.

The consumers use smartphones not only for buying online, they use it for browsing the product information, product reviews, price comparisons, consulting friends and families prior to shopping. (Babbitts, 2013).

In the art of mobile marketing the effectively and efficiently mastered strategies can lead to strong positioning of their brands in their respective market. The common hurdle in the online shopping results from the non-user friendly mobile site (Emarketer, 2013).

\section{A. Mobile Marketing}

Definition: Michael \& Salter (2006) defined mobile marketing as a set of practices that enhances engagement and communication of organizations with their audience in a manner that is interactive and relevant through the use of mobile devices or networks. Mobile marketing can be used to enhance the promotion ideas, services and goods so as to bring forth the value for the esteemed shareholders.

Balasubramanian (2002) and Siau et al., (2005) had explained how the recent advancement in mobile technology made it easy for the consumers to surf the Internet, find locations with GPS, watch movies, play games, and so on. The increased exposure to the mobile marketing engaged the consumers towards accepting the mobile marketing. Deng et al. (2010) define mobile marketing acceptance as "an individual consumer's propensity to accept new technologies and use them in a way that they will find useful”. Bauer(2005) and Gao (2010) had studied mobile marketing and stated mobile marketing as the use of mobile to personal information, provide others with specific locations, one-to-one communication, and for entertainment.

\section{LITERATURE REVIEW}

Mobile marketing has been an effective activity where the companies make significant sales to the already acquired customers. Through this marketing, there is a possibility of retaining customers due to the communication process that is done between the company representatives and individual customers. There is an assurance that, the sent messages will definitely get to their intended destinations or individuals. Mobile marketing is highly innovative and a relevant tool in 
direct marketing in that an assumption that customers' have and must use their mobile phones (Anckar \& D’Incau, 2002).

From their case study, Eois McRae et al (2013) have demonstrated that consumers have stronger emotional responses to their site visits/branded app use when the visit is conducted on a mobile platform than other platforms. The consumers have trust on the brand messages receive The consumers had more trust on brand messages received on their mobile than the messages from other communication devices. Dr. John AkpesiriOlotewo and Dr. Samson OluwaseunFadiya, (2015) had explained that Mobile marketing has gained immense popularity in the contemporary business world because of its convenience in sending personalised promotional messages to individual customers.

\section{A. Determinants of Mobile Shopping Behaviour}

Personality factors: Joaqui'nAlda's-Manzano, et al (2009) have studied about the drivers of M-shopping acceptance and they explore the individual personality factors. They have used the unified theory of acceptance and use of technology (UTAUT) model (Venkatesh et al.,2003) to focus on three variables that approximate fit between the individual personality and the mobile phones medium: innovativeness or the degree of interest in trying a new concept, or an innovative product or service (Rogers, 1995); affinity, conceptualised as the perceived importance of the medium in the life of the individual (Rubin, 1981) and compatibility or "the degree to which an innovation is perceived as consistent with the existing values, past experiences, and needs of potential adopters (Rogers, 1995, p. 224).

Affinity to mobile telephones has a direct and positive influence on the intention to engage in M-shopping, same as findings of previous research focused on mobile phones (Bigne' et al., 2007). This implies that the more the affinity to mobile phones, the higher the probability of acquiring services through mobile phones. Companies which use the mobile phone as a shopping channel should be able to offer new, innovative services and contents with added value to improve consumers' affinity to mobile phones, as it would allow consumers to maintain a relationship with this medium and increase the probability of purchase. Compatibility, as the degree in which mobiles are consistent to past experiences with distance shopping methods, has a positive influence on the intention to engage in M-shopping, suggesting that a consumer who has previously shopped through the internet is more likely to make a purchase via a mobile phone in the future. (Rogers, 1995; Yang, 2005). Consumers who have purchased a product or service through the internet have broken the barriers to distance shopping and therefore are more predisposed to M-commerce (Sivanad et al., 2004).

Kiseol Yang (2010), have studied about the determinants of consumer mobile shopping services adoption. From UTAUT model he have explored the drivers that accelerate US consumers' mobile shopping services adoption behaviour. which includes performance expectancy, effort expectancy, social influence, and facilitating conditions are employed to determine.

Utilitarian performance expectancy: Kleijnen et al. (2007) had proved that the flexibility of use, consideration of time and place, personalization, and shopping effectiveness reflect utilitarian performance. consumers would have a positive attitude toward using mobile shopping services when it help consumers save shopping time, compare product prices, and get relevant promotion information in their hands at user pinpoint locations. Hedonic performance expectancy: Babin (1994) and Holbrook (1999) have explained hedonic performance expectancy as the experiential and emotional aspects of services derived from the multisensory, emotive, and entertainment aspects of experiences in the consumption process.

Venkatesh(2003) had referred Effort expectancy as the degree of ease of use of the technology. Social influence is defined as the degree to which an individual consumer perceives how important others believe he or she should adopt mobile shopping services. (Ajzen, 1991: Venkatesh and Davis, 2000).Facilitating conditions included the technical infrastructure exists to support the use of the technology (Venkatesh et al., 2003).

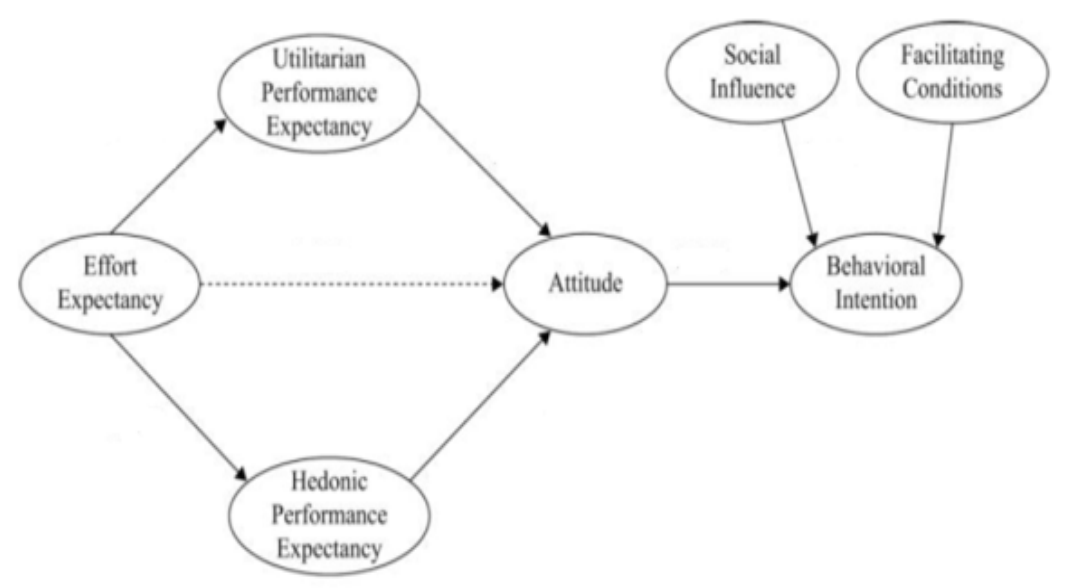

Figure 1: UTAUT Model. Kiseol Yang (2010) 


\section{B. Behavioural Intentions}

Sonia San-Martín, 1 and MaríaA.Ramón-Jerónimo (2015) have proposed the model which is the extension of the TAM (Davis, 1989) that used the Theory of Reasoned Action (TRA) (Fishbein and Ajzen 1975; Ajzen and Fishbein 1980), which suggests that subjects' behavioral intentions merge two types of factors: attitudinal (of a personal nature, perceived control) and behavioral (based on social influence, and referred to as subjective norm).

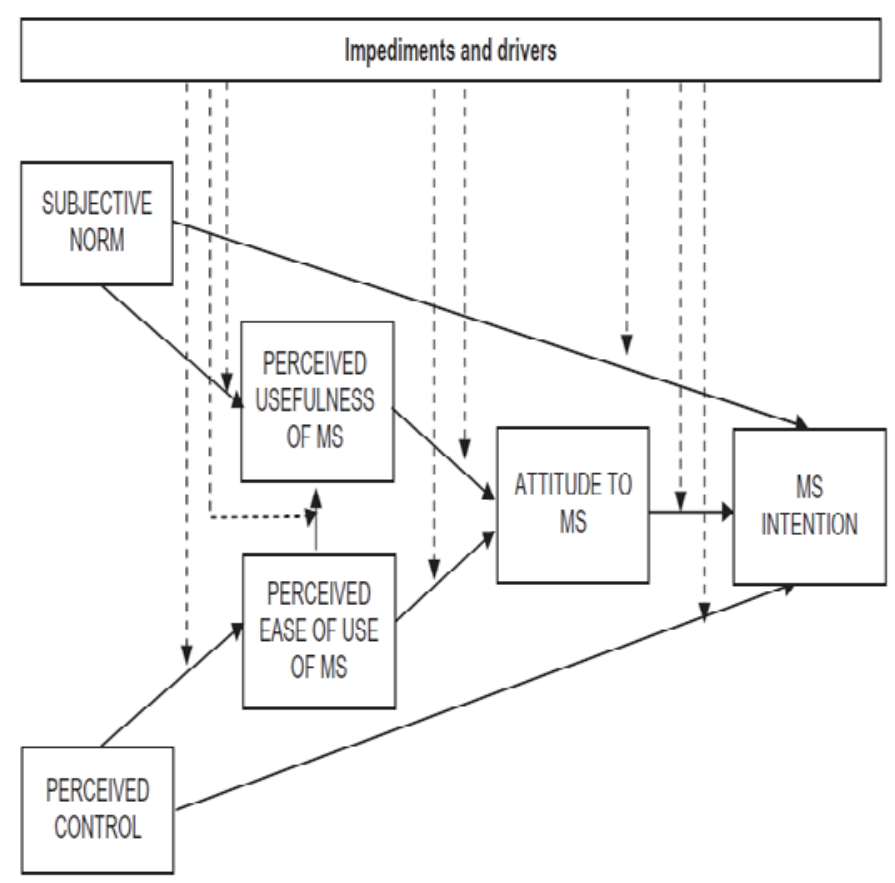

Figure 2: TAM with Behavioural Intentions. San-Martín et al, 2015

Due to the limited size of mobile screen, more steps and processing page is needed whenever a consumer transact using their mobile device. Since PEOU is another important variable to predict consumers' intention to adopt m-shopping, practitioners should optimize their websites for mobile usage such as the ease of navigation and accessing websites from consumers' mobile phone.

Subjective Norm is also significant in predicting the consumers' intention to adopt m-shopping. The emphasis should be concentrated on selecting social networks which have the greatest media impact on consumer, e.g., 'Facebook', 'Friendster' and etc. Practitioners can also consider conducting seminars by inviting opinion leaders, celebrities or experts in mobile phone.

PR is insignificant with the consumers' intention to adopt $\mathrm{m}$-shopping. During the process of payment in transactions, practitioners should implement transparency management. Further attention should also be given in developing better security features to reduce transaction risk such as the risk of misuse of credit card information. All of these will be useful in improving consumer's belief in the system security. (Choy Har Wong et al, 2012).

\section{Mobile Shopping Motivation}

Kiseol Yang (2010), have implied in the shopping motivations as push factors of mobile shopping in their study to determine the shopping service adoption. The determinants of mobile shopper's service adoption includes Idea, efficiency, adventure, and gratification shopping motivations. They have suggested that these determinants need to be incorporated into the development of mobile shopping service functions and features to satisfy consumer shopping experience in the mobile shopping channel.

1) Utilitarian shopping motivation reflects shopping activity as work (Babin et al., 1994) and it is the motivation for convenience and time savings (Jarvenpaa and Todd, 1997; Teo, 2001). Utilitarian shopping motivation emphasizes that consumer shopping behavior is guided by the functional features of the products/services as well as financial desires (Kim, 2006).

2) Hedonic shopping motivation. In contrast to utilitarian shopping motivation, hedonic shopping motivation emphasizes the consumer's emotional feelings and psychological sensations (Westbrook and Black, 1985; Arnold and Reynolds, 2003; Kim, 2006) and shopping for entertainment purposes (Mathwick et al., 2001; Kim, 2002).

3) Social shopping focuses on the aspect of social influences of important others and interpersonal relationships with others during a shopping trip (Arnold and Reynolds, 2003; Kim, 2006). Since consumers consider shopping as an opportunity to socialize with others (Cardoso and Pinto, 2010)

4) Gratification shopping refers to shopping that brings good feelings (Tauber, 1972) and special treats to the individual consumer (Kim, 2006). Consumers shop for reducing tensions (McGuire, 1974) and escaping from a problem (Lee et al., 2001). In the mobile shopping environment, personalized services and promotions to each individual mobile phone user can be provided as a personal treat (Jones and Issroff, 2007).

5) Idea shopping is a consumer shopping activity when the consumer is likely to engage in collecting information about new trends and fashion (Kim, 2006). The easy access of up-to-date information and promotions for products and services in the mobile shopping channel may enable shoppers to find out variety of product information and services, thus, it will increase consumer idea shopping motivation.

6) Role shopping emphasizes shopping for others to successfully find the right gift (Arnold and Reynolds, 2003). When applying role shopping to the mobile shopping context, the personal property of the mobile phone provides shoppers a tangible sense of ownership showing the person's role in sharing information and opinions in the mobile shopping channel (Jones and Issroff, 2007). In addition, an onthe-go personal device of mobile phone enables shoppers to obtain product information anytime and anywhere, enhancing a person's role to find out the right product at the right time. 
7) Value shopping refers to the consumer shopping process of focusing on bargain hunting as well as discount seeking behavior (Arnold and Reynolds, 2003) and is described as consumers' desire for inexpensive shopping opportunities (Wagner, 2007). In relation to the mobile shopping channel, consumers can acquire coupons through their mobile applications on the move. In addition, several discussion forums on the mobile internet enable consumers to share discount information with other members, resulting in the ability to find the bargains effortlessly via the mobile shopping channel.

8) Gratification shopping is significant in the mobile shopping channel. Since mobile phone is an extremely personalized device that users carry most of the time, retailers can send personalized and individual messages or promotions. With GPS function being a ubiquitous characteristic of mobile devices, locationbased mobile shopping services are available to consumers regardless of temporal and spatial constraints. When consumers receive personalized shopping information based on a specific location, they would be likely to feel the special treatment from retailers and engage with the retailer or brand.

\section{Mobile Brand Interaction}

KaeAhanonu, et al( 2013) have studied about the brands, and how brands in south Asia can go beyond traditional advertising and deeply engage with consumers via mobile to generate brand loyalty among them.

Brand engagement: Brand engagement is the method by which brands connect and interact with their intended consumers with the purpose of creating and sustaining awareness of their brand. The mobile platform allows an always-on connectivity with consumers and can be highly localized and personalized, quickly making this one of the most effective channels that businesses can use to achieve brand engagement.

\section{E. Company Strategies \& Examples}

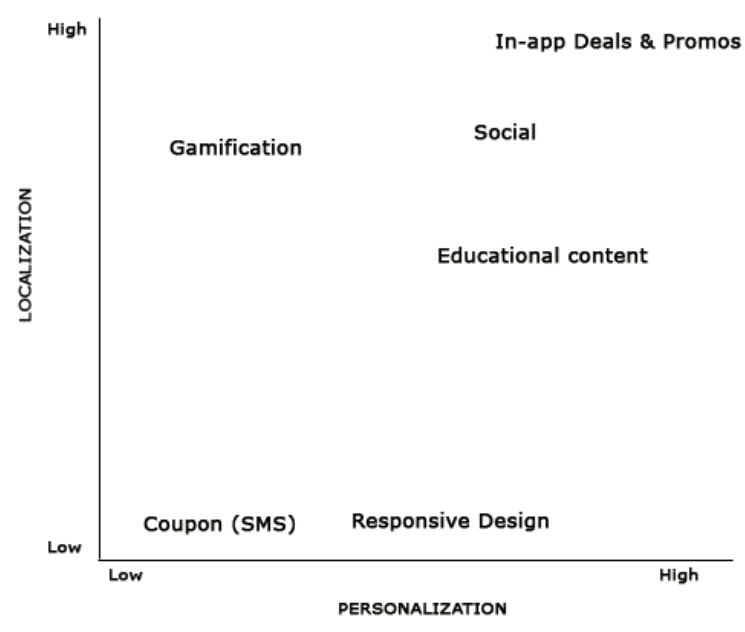

Figure 3: Personalization and Localization Features of Various Engagement Tactics

\section{F. Social Strategy}

In today's environment mobile has become inherently social with consumers spending hours at a time on social sites such as Facebook, Twitter and Instagram. These social media platforms enable the brands to interact with their users in a personalized and localized fashion.

\section{G. Other Elements of Mobile Strategy}

The marketing strategies include responsive design, gamification, educational content generation and couponing.

1) Responsive design is about adjusting website elements based on the detected mobile device screen size. It affects the total cost and overall complexity, as well as increases localization challenges.

2) Brands looking to take small, low-cost steps into mobile can take advantage of the popularity of games by collaborating with the studios that produce them. Some companies can take a different approach and create their own game, all with the same objective of increasing consumer interaction and customer loyalty.

3) An example of effective gamification is the iButterfly app created by Dentsu Mobius. This app was built for a local mall in Singapore to entice customers to shop in their stores. The consumers can catch the butterflies on their mobile device. Each butterfly contains a coupon or some other incentives to visit a store in the mall (M. Briant, personal communications, June 3, 2013).

4) Educational content on mobile is big across the region for both consumers and brands. Content provides useful information for a particular demographic which enables to drive interaction. An example is educational Apps for the competitive exams. Theses apps have the features to calculate the student's ability and according to their grade level they provide the personalised coaching and assessments. This utility provides access to a customer when they are in need of service or information, positioning the brand as a solution to their problem when they become in-market for goods or services.

5) Coupons and deal-based campaigns are also used heavily in the mobile marketing. In Southeast Asia, consumers are open to advertising on mobile specifically. S.Danapalan (2013) had noted that the rate of acceptance in the United States was low, while the Malaysians in train stations accepted $30 \%$ of ad messages and nearly $60 \%$ in shopping malls.

6) Educating Brands on Mobile Marketing:

7) Brands should consider the value of mobile marketing and also should develop unique campaign using mobile devices. Besides understanding value, there should be focused coordination between the marketing department which drives users experience and the IT department which drives platform choices, to generate a positive brand experience.

\section{H. Mobile Phone Location-Based Advertising (MLBA)}

Aaron Gazley, et al (2015) analysed the effects of locationbased services. They have explored the consumer purchase 
intention at point of purchase. They have tested a conceptual model, analysing the effects that features of mobile phone location-based advertising (MLBA) services (customisation, permission and intrusiveness) have on attitudes and purchase intentions, using the theory of interactive advertising. The factors that have a direct effect on consumer attitudes towards MLBA messages, and subsequently purchase intention includes Customisation, permission and intrusiveness. The effect of receiving such messages at point of purchase (POP) was assessed.

Interactivity can be the immediately iterative process by which customer needs and desires are uncovered, met, modified and satisfied by the providing firm (Bezjian-Avery et al.,1998) defined The more intrusive a message is perceived to be, the less positive a consumer's attitudes towards the message will be. When the consumer opts-in, attitudes towards the message will be more positive. Attitudes will be more positive for messages that are received at POP than for messages that are not. The more positive a consumer's attitude towards the message, the higher their level of purchase intention at POP.

Intrusiveness still plays a big role in determining attitudes, despite the opportunities offered by smartphones for permission-based marketing and greater user control (Watson et al., 2013). Intrusiveness can be countered by permission (opting-in) and user control through customisation. (Storm et al., 2014)

\section{Managerial Implications}

Based on the finding of this study, the following implications are recommended to mobile marketers. First, consumers will adopt mobile shopping services if they believe using the mobile shopping services helps them to increase gains in shopping performance (e.g., saving shopping time, obtaining promotion information, or receiving customized product/service information). The ubiquitous advantage of mobile shopping services that can be accessed anytime and anywhere would be a significant driving factor affecting consumer intention to use mobile shopping services. If consumers find difficulty getting or facilitating mobile shopping services in achieving their shopping goals, it would make them frustrated with the services. Thus, retailers and mobile marketers should examine the functionality and usability of mobile shopping services from the customers' perspective and design the shopping services that are easy to access and navigate.

The entertainment aspect: Mobile shopping services need to be designed to enhance shopping enjoyment in order to create consumers favourable shopping experiences. Budiu, (2009) stated about the optimized shopping experiences by integrating the retailers' regular website and the services. The hedonic performance of the service providers satisfies consumer expectation and the positive attitudes toward the service provider will be further created. (Fiore et al., 2005).

Regarding the sociological aspect, Consumers will be influenced by word-of-mouth and important others' opinions in using mobile shopping services. They may access social networking sites to get information for popular mobile sites or opinions from others regarding a product. Retailers and mobile marketers should make product review sites or expert recommendation features available to consumers in store via mobile shopping services.

The technological infrastructure of the retailers and marketers should provide their mobile sites with a userfriendly interface. It is crucial to design mobile sites and interfaces for two types of mobile phones: high-end devices (e.g., iPhone, Blackberry Storm) v. low-end devices. (Budiu, 2009). It is recommended in mobile marketing that retailers should:

1) Retailers should value the mobile channel from other internet channels.

2) Accept that for the present at least the mobile channel is more about marketing and promoting products, than about direct sales, and develop their strategies accordingly; it is likely that many items browsed on a mobile may be purchased online through a computer or in store.

3) Develop an understanding of the way in which consumers use the mobile channel for their specific product portfolio, and customise their offering and communication accordingly.

\section{J. Pros and Cons of Mobile Marketing}

Mobile marketing makes the process of advertising very cheap and convenient. Mobile marketing helps the company to realize maximum profits with the less expensive MMS and SMS services when compared to expensive television and print adverts (Michael \& Salter, 2006). The use of mobile phones is the best for it enhances privacy and ensuring that there is personal communication with the concerned individual.

It is a quite effective in that consumers are reached wherever they are, because of the mobile phones. The potential consumers can be reached through the use of phones (Leek \& Christodoulides, 2009).

Loyalty of consumers as well of that of companies can be assured. Personalised communication and interaction with the potential consumers to give promotions and award are the added benefits. The intrusion done by the mobile mar-keting have a negative attitude towards the brand and even end up discouraging would-be consumers.

\section{K. Ethical Issues in Mobile Marketing}

1) Hacking the computer systems or the internet systems

2) Threat to identity

3) Threat to location

4) Threat to information

5) Threat to choices

\section{CONCLUSION}

Here we gathered useful research data on consumer behaviour in the context of mobile shopping. The studies that focused the smart phone usage in the marketing is very limited. There is considerable scope for further research. The research can be more specific to the different stages in the consumer decision-making process, and in respect of different product categories. Interestingly, there is a high level of use of the mobile phone in the information search and review of 
alternatives parts of the process, and some use for pre-purchase activities, but a low level of use for purchase transactions. For all products, the mobile marketing can be utilised in evaluating alternatives, and in pre-purchase activities such as checking stock or finding a discount voucher or promotion, even in low involvement purchases. 